\title{
Effect of melt viscosity on the ejection force in injection moulds
}

\author{
A. J. Pontes, A. M. Brito, A. S. Pouzada \\ Department of Polymer Engineering, University of Minho, \\ Campus de Azurem, 4800-058 Guimarães, Portugal
}

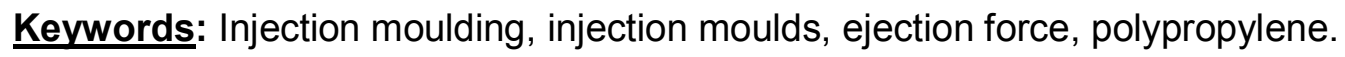

\begin{abstract}
This paper shows data on the ejection force of injection mouldings. The tubular mouldings are pin gated. Two polypropylenes with different melt viscosities (melt flow indices) were investigated. Experimental focus is put on the effect of the holding pressure, mould temperature and the cooling time on the measured ejection force. Pressure and temperature were continuously monitored with transducers during the filling process. The ejection force was directly measured with load cells. The results show that higher viscosity lends to higher ejection force.
\end{abstract}

\section{Introduction}

The development and manufacture of injection moulds for high quality technical parts are complex tasks involving the knowledge of the injection moulding process and the material changes induced by processing. In the case of some specific shapes (boxes, cylinders) the shrinkage is partially restricted by the mould. The moulding shrinks against the core, inserts or pins. Thus, upon ejection, it will be necessary to overcome the frictional forces resulting from the shrinkage. This aspect has significant implications in the mechanical design of the injection moulds especially when deep cavities are involved. In the design of these moulds, the accurate prediction of the ejection force may contribute for a more precise and economically efficient decision of the ejection system. In fact, if the designer knows the force likely to be required during the moulding ejection, it will be possible that a proper decision can be made for a less complex and cheaper ejection system: mechanical, pneumatic, or hydraulic [1,2]. The capability of predicting the ejection force may also help to optimising the mould design and to guaranteeing the structural integrity of the mouldings.

In this work a study on the influence of the viscosity was envisaged. The effect of processing variables (mould temperature, holding pressure and cooling time) on the ejection force for deep tubular mouldings was assessed using two polypropylenes with different melt flow indices.

\section{Experimental}

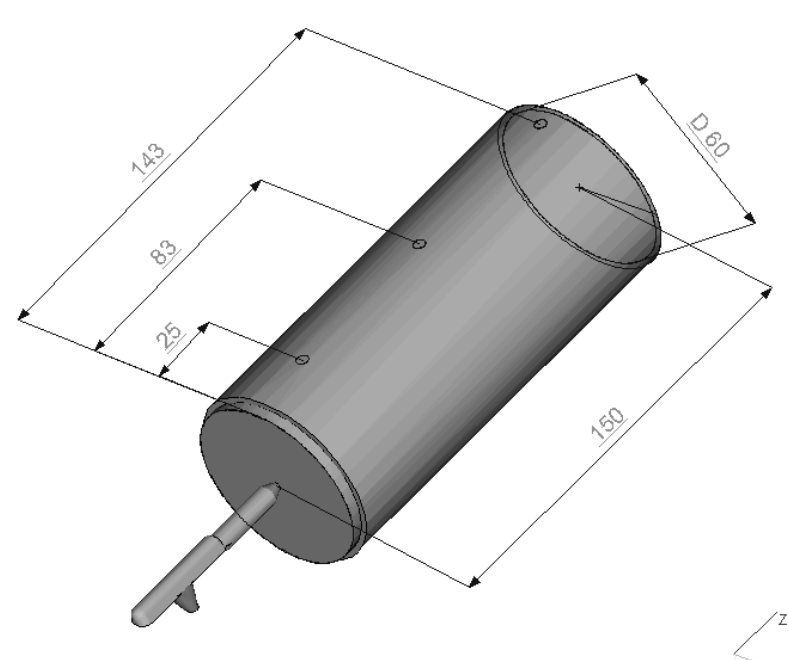

Fig. 1. Moulding dimensions and pressure transducer locations
Materials. Two commercial injectionmoulding grades of polypropylene (PP) from Targor, were used.

These grades have different melt flow indices: the MFI $\left(230^{\circ} \mathrm{C} / 21.6 \mathrm{~N}\right)$ is of $2 \mathrm{~g} / 600$ s for the Moplen HP456H grade and $12 \mathrm{~g} / 600 \mathrm{~s}$ for the Novolen $1100 \mathrm{~N}$.

Moulding. The studies were based on tubular mouldings $(60 \mathrm{~mm}$ in diameter, $146 \mathrm{~mm}$ in length, and $2 \mathrm{~mm}$ in thickness) filled with a parallel flow (Figure 1). The research mould described elsewhere $[3,4]$ is instrumented to measure and record ejection force, pressure and temperature upon production of the 
moldings. The injection unit cell consisted of a Ferromatic Milacron K85 injection-molding machine of. $850 \mathrm{kN}$ clamp force and a thermal regulator, Klöckner Ferromatic Desma - T10EW403 The ejection force of a moulding is derived from the two curves of the force evolution during ejection given by the load cells, and is calculated as

$\mathrm{Fe}=\mathrm{F} 1+\mathrm{F} 2$

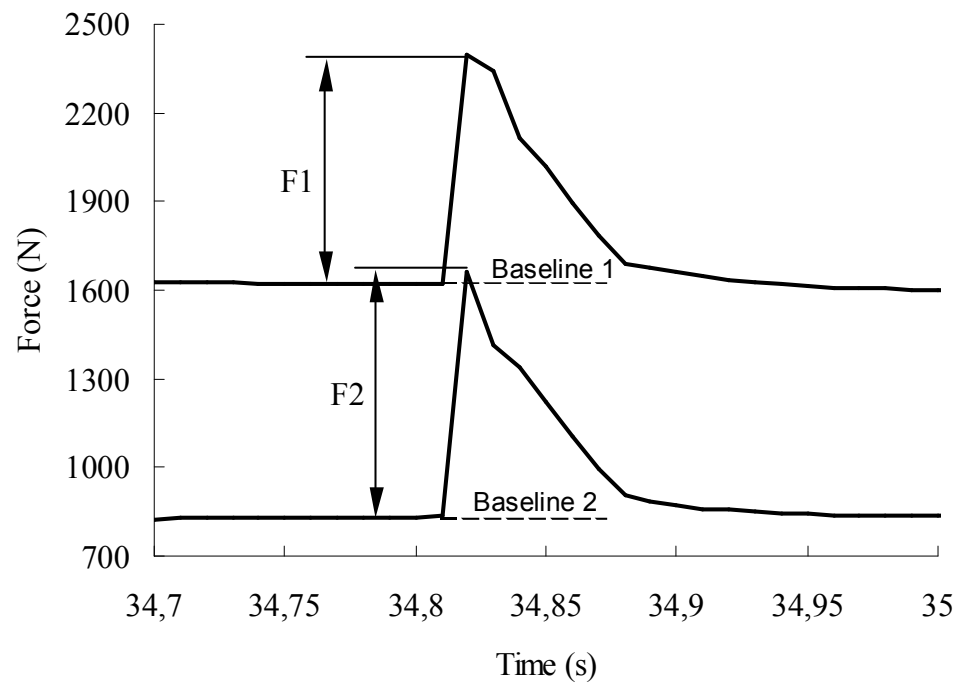

Fig. 2. Typical force evolution during ejection
Typical evolution curves are shown in Figure 2. For each processing condition the ejection force was characterized by the average of the data from 5 consecutive mouldings. The melt and mould temperatures were set at $210^{\circ} \mathrm{C}$ for both materials. In order to achieve the same injection time for the two materials, for they having different melt viscosities different injection pressures were used. The varying processing parameters were the mould temperature (Tw), the holding pressure $(\mathrm{Ph})$, and the cooling time (ta).

All other processing parameters were kept constant. The conditions of the series of experiments are listed in Table 1.

Table 1. Processing conditions

\begin{tabular}{|l|c|c|}
\hline Mould temperature & ${ }^{\circ} \mathrm{C}$ & $28,43,60$ \\
\hline Holding pressure & $\mathrm{MPa}$ & $10,20,30$ \\
\hline Cooling time & $\mathrm{s}$ & $10,20,35$ \\
\hline Holding time & $\mathrm{s}$ & 18 \\
\hline
\end{tabular}

\section{Results and discussion}

The ejection force of tubular injection mouldings depends on a number o factors depending on the type of material, the processing conditions and the roughness of the core. The following expression [5] describes the influence of the main variables

$$
\mathrm{F}_{\text {ejec }}=\mu \cdot 2 \cdot \pi \cdot s \cdot \mathrm{E}\left(\mathrm{T}_{\mathrm{e}}\right) \cdot \mathrm{L} \cdot\left(\varepsilon_{\left(\mathrm{T}_{\mathrm{rom}}\right)}-\alpha \cdot\left(\overline{\mathrm{T}_{\mathrm{e}}}-\mathrm{T}_{\mathrm{room}}\right)\right)
$$

where $\mu$ - coefficient of static friction, $s-$ thickness, $E\left(T_{e}\right)-$ modulus at average ejection temperature, $\mathrm{L}$ - length of the part in the direction of ejection, $\varepsilon\left(\mathrm{T}_{\text {room }}\right)$ - diametrical shrinkage at room temperature, and $\alpha$ - coefficient of thermal expansion

Effect of the mould temperature. The ejection force data for both materials as a function of the mould temperature are shown in the Fig. 3.

For a constant cooling time, ta, the ejection force varies inversely to the mould temperature. This result is expected since the increment of the mould temperature corresponds to a higher temperature of the part at ejection. The increase of the mould temperature lends to a reduction of the elastic modulus and of the shrinkage at ejection. This dual effect contributes to reduce the ejection force. 


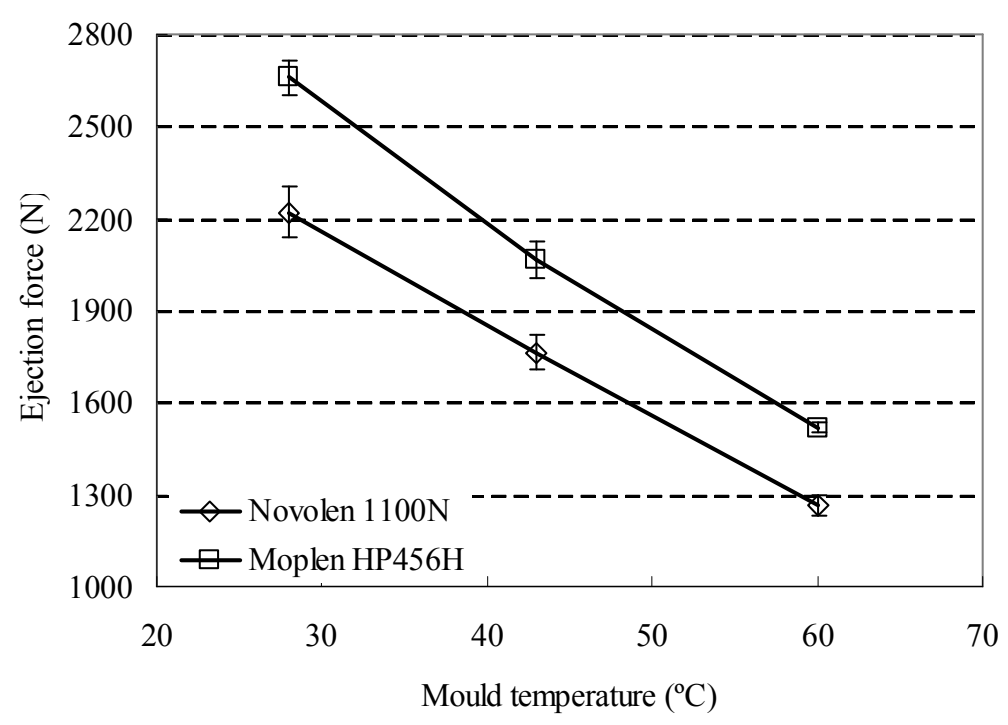

Fig. 3. The influence of mould temperature on the ejection force. Mouldings were produced with $\mathrm{Ph}=20 \mathrm{MPa}$ and ta $=20 \mathrm{~s}$
The results also show that the evolution of the ejection force as a function of the mould temperature is similar for both materials. The ejection force is bigger for the lower MFI Moplen HP456H that has a greater viscosity. This behaviour is expected since the increase in the viscosity makes difficult the pressure transmission during the holding phase. Consequently the diametrical shrinkage increases in comparison to more fluid materials.

Effect of the holding pressure. The experimental ejection force data for the tubular mouldings when the holding pressure is

varied are shown in Fig. 4. The holding pressure for both materials affects only slightly the ejection force. It is expectable that a force reduction is associated to the rising pressure. This apparently controverse fact results from the contact pressure between the moulding and the core being smaller in result from the decreasing diametrical shrinkage arising from the holding pressure increase. Therefore a smaller force is required to eject the part.

For case of the material of higher viscosity, the Moplen HP456H with MFI of 2, the ejection force data is not affected when the holding pressure is changed. This results from the increase of the viscosity making the pressure transmission difficult during the holding phase; consequently, the cavity pressure profiles are not affected by the increase of the holding pressure.

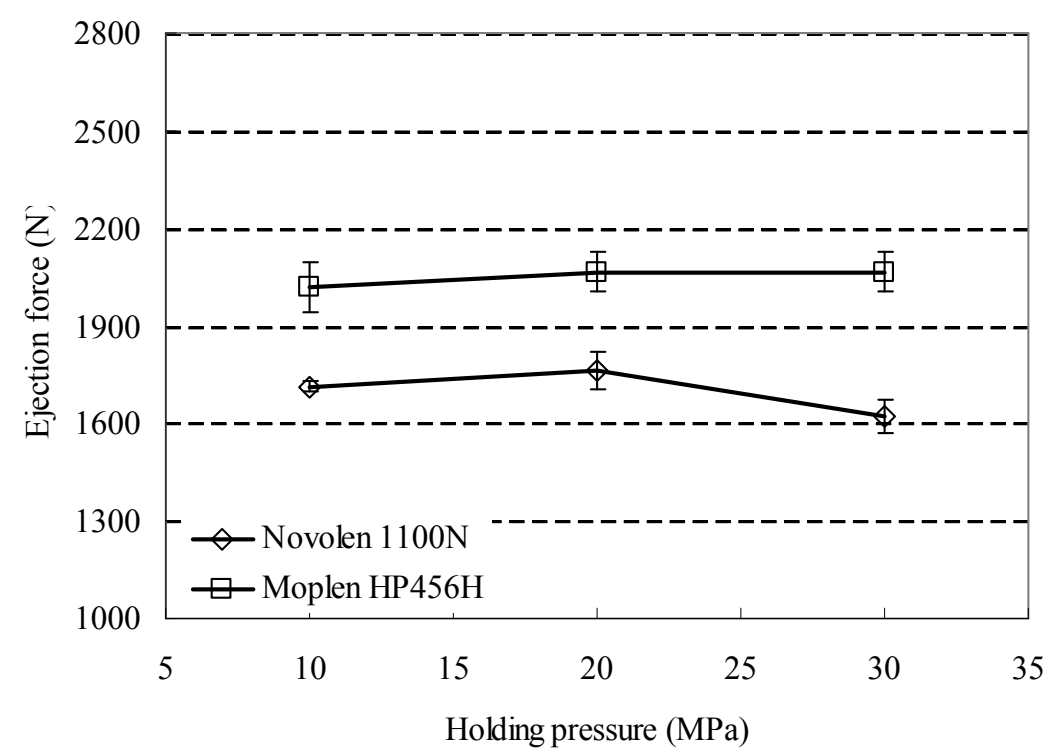

Fig. 4. The influence of holding pressure on ejection force. Mouldings produced with $\mathrm{Tw}=43^{\circ} \mathrm{C}$ and ta $=20 \mathrm{~s}$.

Effect of the cooling time. The ejection force data shown in the Fig.5 represents the effect of the cooling time for both materials.

If the mould temperature, Tw, is kept constant, the ejection force increases as the cooling time increases, the evolution being similar for both materials. Since the increment of the cooling time determines a lower part temperature at ejection a higher skrinkage results and the results reflect it. 
Furthermore, the decrease of the part temperature results also increases the elastic modulus, this effect also contributing to the increase the ejection force.

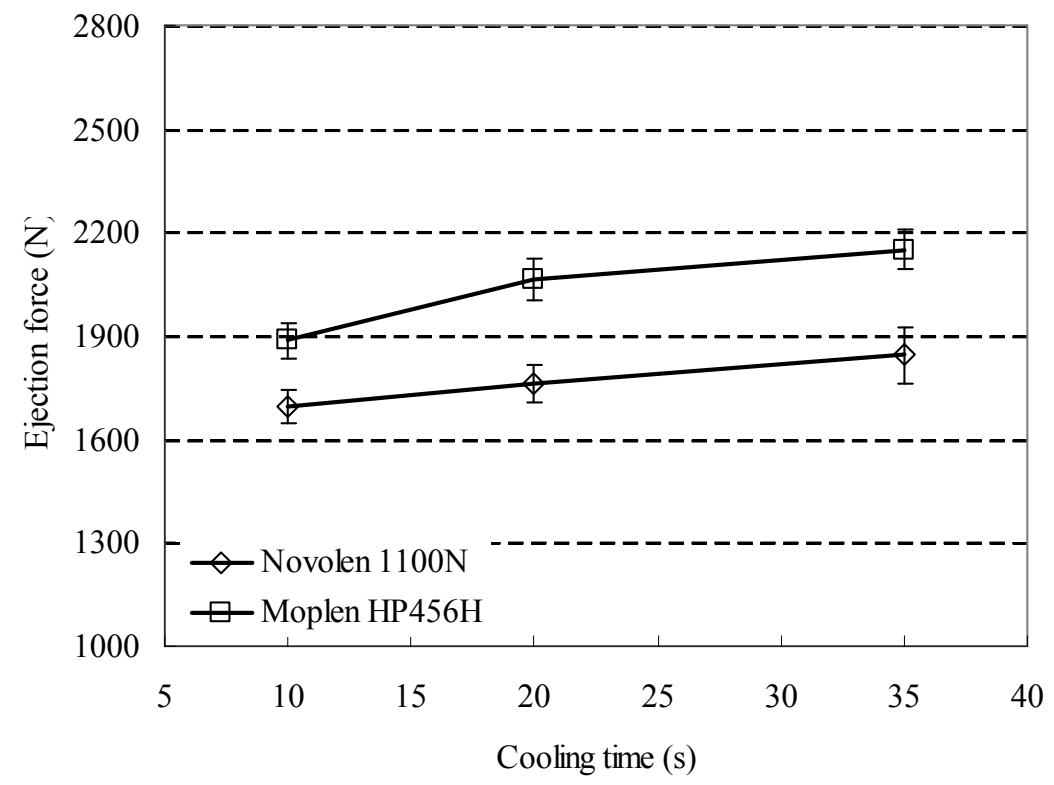

Fig. 5. The influence of time to ejection. Mouldings with $\mathrm{Tw}=43^{\circ} \mathrm{C}$ and $\mathrm{Ph}=20 \mathrm{MPa}$.

\section{Conclusions}

The melt viscosity of similar materials influences the ejection of injection moulded deep parts.

Irrespectively of the melt viscosity (that is relatable to the MFI), the holding pressure has a slight influence on the ejection force. However, for the case of the material with higher viscosity, or lower MFI, the holding pressure does not affect the ejection force. The lower pressure transmission due to the high melt viscosity during the holding phase is responsible for this behaviour.

The results also confirm that the mould temperature is the studied variable that has the major influence on the ejection force and its evolution does not depend on the melt viscosity.

Also, the ejection force increases as the cooling time increases as a natural consequence of the higher thermal shrinkage and of the bigger modulus of the material at ejection.

\section{References}

[1] G. Menges, and P. Mohren: - How to Make Injection Molds, Hanser, New York, (1993).

[2] R.G.W. Pye: Injection mould design. 4th ed. Harlow: Longman Scientific \& Technical, 1989. 754 p. ISBN 0-582-01611-8

[3] A.M. Brito, A. J. Pontes, A. Febra, J. Oliveira, A. Selada, A. S. Pouzada: O Molde, Vol. ${ }^{050}$ (2001), p.56.

[4] A. J. Pontes, A. M. Brito, A. S. Pouzada: J. Injection Molding Technology, Vol. 6: no 4 (2002), p. 343.

[5] A.J. Pontes, R.Pantani, G.Titomanlio, A.S. Pouzada: Proceedings ANTEC 2002 Conf, San Francisco: May 2002. paper 534. 